\title{
The placebo effect and ethics in medical practice
}

Placebo has been part of medical practice for many centuries, and the term comes from Latin; it means "I will please." For many years, many physicians considered that the substance that produced the placebo effect meant that contents were not appropriate. However, they assumed that its action could be conventional, and it stayed that manner by way of habits. Then, several physicians realized that, although the substance was not appropriate, its administration to patients could improve their status with therapeutic management. Later, more recent investigations have demonstrated that the placebo effect is a psychological and psychophysiological event; therefore, it is considered to be a therapeutic context. For some years now, it is also known that the main component of placebo is the psychological factor, and this is because the consequences are purely physical, as when pain is gone or relieved. Pain relief due to the placebo effect is one of the actions that interests the scientific community the most given that published studies have shown that it may adequately replace opiates' actions. Placebo substances referred to as "pure" usually contain a sugar pill or saline solution; thus, physicians may use a placebo themselves in an attempt to calm patients or at the patient's own request. Effects are only limited to solve relatively superficial symptoms and in the case of psychological imbalances, but they are not enough to completely cure an underlying disease.

Therefore, the placebo effect is described as psychophysiological, i.e., encompassing both its effect on the body as well as on the mind. Among the main psychophysiological results, the most relevant one is hope, followed by expectations of certain responses, the power to reduce anxiety, encouragement, certain conditioning, a good analgesic outcome, and somatic-related effects, etc.

Placebo administration may promote an improvement or eventually a cure, although it will depend on the disease, the patient's personality, and also the physician's skills and expectations when using a placebo.

The rate of placebo use is high in the field of complementary and alternative medicine (CAM). In a teaching hospital of the USA, $80 \%$ of attending physicians admitted they had occasionally used placebos in their clinical practice; in Denmark, $48 \%$ of family physicians had prescribed placebos several times throughout a 1-year period.

However, it has not been established whether CAM is actually effective due to its action or because of what patients assume through positive expectations that leave them satisfied and, also, because they maintain a good relationship with their physician thanks to their listening and understanding. This is the case when patients receive a detailed oral explanation about the medication and its potential effects. However, the indication is not always correct, either because physicians do not clearly explain the medication's effect or indicate its result, thus manipulating patients.

Different aspects that may refer to the actual effectiveness of CAM are still being defined through several studies that have performed scientific assessments of different therapeutic results in certain conditions and disorders. The studies that have been mostly considered in the CAM modalities have been assessed mainly by the Cochrane Library group.

Homeopathy is the subject of multiple investigations conducted by Cochrane because, from a scientific perspective, its outcomes should be discussed since, in practice, minimal doses are usually indicated, even for severe conditions. Therefore, medicine cannot point out whether homeopathy is adequate for any disease because it is an individualized therapeutic approach; an inadequate assessment may lead to severe patient disorders because physicians end up being disrespectful of ethics.

In relation to placebo use in randomized clinical trials, this is the field of medical ethics because several actions are inappropriate. Clinical trials are usually divided into two patient groups: one group receives the drug and the other, called the control group, a placebo. In medical practice, this action first emerged in the $20^{\text {th }}$ century, especially after World War II, and progressively showed a marked increase. In the context of therapeutic innovations, the methodology was slowly included; thus, in those years, first emerged science in medicine and then, evidence-based medicine. Unfortunately, this type of medicine was invaded by commoditization and its inappropriate commercial interests. This phenomenon increased tremendously, especially 
in some pharmaceutical industries and in the overwhelming technology use. Thus, ethical actions should always be present because an inadequate placebo use leads to a non-scientific, inadequate attitude.

Likewise, there is a growing demand for CAM, which also poses some ethical problems. For an appropriate assessment, several aspects may be implemented in combination, based on qualitative research methods applied to epistemology.

\section{José María Ceriani Cernadas \\ Editor-in-chief}

http: / / dx.doi.org/ 10.5546/ aap.2020.eng.370

To cite: Ceriani Cernadas JM. The placebo effect and ethics in medical practice. Arch Argent Pediatr 2020;118(6):370-371.

\section{REFERENCES}

- Weimer K, Gulewitsch MD, Schlarb AA, Schwille-Kiuntke J, et al. Placebo effects in children: a review. Pediatr Res. 2013; 74(1):96-102.

- Grelotti DJ, Kaptchuk TJ. Placebo by proxy. BMJ. 2011; 343:d3435.

- Curie A, Yang K, Kirsch I, Gollub RL, et al. Placebo Responses in Genetically Determined Intellectual Disability: A MetaAnalysis. PLoS One. 2015; 10 (7):e0133316.

- Bolton P, Shotton L, Young A, Grace J. The ethics of using placebo medication in a non-capacitous patient. Brain Inj. 2012; 26(11):1397-400.

- Colloca L, Barsky AJ. Placebo and nocebo effects. N Engl J Med. 2020; 382(6):554-61.

- Guerreiro Fregnani JH, Lopes Carvalho A, Rocha F, Souza Viana L, et al. Ética del uso del placebo en la investigación clínica: propuesta de algoritmos para la toma de decisiones. Rev Bioét. 2015; 23(3):456-67.

- Stub T, Foss N, Liodden I. "Placebo effect is probably what we refer to as patient healing power": A qualitative pilot study examining how Norwegian complementary therapists reflect on their practice. BMC Complement Altern Med. 2017; 17(1):262. 